\title{
LOS SALARIOS Y LA DESIGUALDAD EN BUENOS AIRES, 1810-1870
}

\author{
WAGES AND INEQUALITY \\ IN BUENOS AIRES, 1810-1870
}

\author{
Jorge Gelman y Daniel Santilli \\ Universidad de Buenos Aires, Buenos Aires, Argentina \\ $<$ jorgegelman@gmail.com>; <dvsantilli@gmail.com>
}

\begin{abstract}
Resumen. En este trabajo se aportan los resultados de una investigación sobre los salarios y la desigualdad en la provincia de Buenos Aires entre 1810 y 1870. Se reconstruyeron series de salarios de empleados del Estado y privados, agrupados en las principales categorías de trabajadores calificados y no calificados, para poder estudiar la evolución de la desigualdad en sus ingresos. Con esta información se ofrecen algunas explicaciones de los cambios vinculados a los de la estructura del mercado de trabajo, los ciclos económicos y la construcción del Estado.
\end{abstract}

Palabras clave: salarios; desigualdad; Buenos Aires; siglo XIX.

Abstract. In this work we offer the results of our research on wages and inequality in the Buenos Aires province between 1810 and 1870. We built wage series of public and private workers, broken into the main categories of skilled and unskilled, as to be able to study the evolution of income inequality. This information allows us to link such changes to those on the labor market structure, economic cycles and state building.

Key words: wages; inequality; Buenos Aires; 19th century.

Fecha de recepción: octubre de 2013. Fecha de aceptación: febrero de 2014.

\section{INTRODUCCIÓN}

$\mathrm{E}$

n este artículo presentamos los resultados de una investigación que tiene por objetivo final estudiar los niveles y la evolución de la desigualdad en la provincia de Buenos Aires, en la actual República Argentina, desde fines del periodo colonial hasta finales del siglo XIX. En trabajos anteriores estudiamos con cierto detalle la distribución de la riqueza entre los propietarios (Gelman y Santilli, 2006 y 2011), ello aportó importantes evidencias sobre los niveles y la evolución de dicha distribución, pero dejaba de lado a aquellos no poseedores de bienes de algún significado, que era la mayoría de la población. En este caso partimos de

Am. Lat. Hist. Econ., año 21, núm. 3, septiembre-diciembre, 2014, pp. 83-115 
la reconstrucción de los salarios de las principales categorías de los trabajadores estatales y privados, calificados y no calificados. Nuestro objetivo inicial en este terreno consistirá en estudiar la evolución de la desigualdad entre los propios asalariados, y en una segunda etapa, no incluida en este trabajo, ensayar diversas mediciones de la distribución funcional del ingreso, comparando la evolución de los salarios con otros precios del mercado, especialmente los precios de la tierra y los bienes inmuebles, de manera tal que podamos observar cómo evolucionan comparativamente los ingresos de trabajadores y propietarios.

El estudio de los salarios y su evolución ha cobrado renovada importancia en los últimos tiempos, ya sea en su más tradicional y valiosa aportación como indicador de los niveles de vida de la población, como más recientemente a modo de indicador indirecto de los niveles de desarrollo de las distintas regiones en largos periodos históricos. Así, Allen (2011), Allen, Murphy y Schneider (2011), Broadberry (2006), Dobado y García (2010), Pomeranz (2000) y Van Zanden (1999) están llevando a cabo grandes proyectos comparativos en el ámbito internacional vinculados a los debates sobre la divergencia o la convergencia, utilizando métodos que permiten contrastar las diversas series, como su conversión a gramos de plata, y tratando de construir índices de precios y canastas de consumo equiparables para comparar salarios con paridad de poder adquisitivo (PPA o PPP, purchasing power parity; sobre este concepto véase Taylor y Taylor, 2004). Igualmente, los salarios pueden ser un insumo importante en los estudios sobre desigualdad al comparar la evolución en las distancias relativas entre los trabajadores calificados y los no calificados, así como entre todos ellos y los precios de los otros factores productivos. En la visión clásica de Simon Kuznets (1966), en los inicios del crecimiento económico moderno en los países en vías de industrialización, se genera un diferencial de productividad en sectores específicos de la economía que se asocia a mejores salarios e ingresos en los mismos que mantienen relación con el resto de la economía, produciendo así un periodo más o menos prolongado de creciente desigualdad, que sólo se modera y en parte revierte cuando el peso del traspaso de factores a los sectores más avanzados es de tal magnitud que tiende a reequilibrar el conjunto, a la vez que los avances tecnológicos se difunden a una parte muy amplia de la economía. Esta visión ha sido muy influyente, al mismo tiempo que discutida en diversos aspectos. En una obra clásica sobre la desigualdad en la historia estadunidense, Lindert y Williamson (1980) analizaron largas series de salarios, comparando la evolución en la relación entre los trabajadores especializados y otros que no lo eran, concluyendo así la existencia de una curva de Kuznets expresada en un incremento de la desigualdad salarial, al menos entre 1820 y la década de 1920, que conoce luego una caída importante seguida de una cierta 
estabilización entre 1950 y 1970. Las explicaciones aportadas eran diversas, incluyendo la oferta y demanda cambiante de factores de producción, como el trabajo calificado y no calificado vinculados a su vez al desarrollo tecnológico, la oferta de educación y su incidencia en la del trabajo calificado, etc. Estudios posteriores matizaron algunos resultados, así como complicaron las explicaciones de los fenómenos observados, aunque no la imagen global de una larga curva de Kuznets en la desigualdad salarial estadunidense, si bien con ritmos y etapas algo distintas (Margo, 1999, 2000). Hay también una discusión sobre la relación entre crecimiento económico moderno y skill premium en la que Van Zanden (2009), Llopis y García (2011) y Van Leeuwen (2004) sostienen que la lógica es inversa a la que está implícita en el planteamiento de Kuznets. Así, en algunos trabajos se postula que la oferta de abundantes recursos humanos calificados espolea el crecimiento moderno y por ende la baja relativa en la desigualdad salarial entre trabajadores calificados y no calificados es condición e indicador de ese despegue económico. De hecho, Van Zanden (2009) sostiene que en el origen de la llamada gran divergencia del siglo XIX a favor del norte de Europa se encontraba en las buenas condiciones de formación y oferta de capital humano en la etapa previa, lo que se demuestra comparando el skill premium de esa región con otras del mundo en las que era bastante más elevado. Por su parte, Llopis y García (2011) y Van Leeuwen (2004) han dado visiones más matizadas respecto al tema.

En la práctica se han encontrado casos históricos diversos y formulaciones distintas sobre estos fenómenos, pero el planteamiento inicial de Kuznets no deja de ser una poderosa hipótesis para pensar la evolución en la desigualdad y dentro de ella de los diferenciales en los ingresos salariales.

Los estudios sobre precios y salarios, sobre todo para etapas preestadísticas, presentan muchas dificultades empíricas y metodológicas que hacen que no abunden los trabajos sistemáticos, lo cual es evidente en la historiografía latinoamericana y argentina. Hay una tradición algo más consistente en los estudios de precios, principalmente a partir de los primeros ensayos sistemáticos emprendidos por Ruggiero Romano (1966) desde la década de los sesenta, luego abordados por un conjunto de historiadores para distintas regiones iberoamericanas, pero son mucho menos frecuentes los estudios sobre salarios.

El trabajo sobre los salarios, además, plantea serios problemas de interpretación en la medida que no es sencillo determinar qué porción de la población percibía sueldos, y a su vez, entre estos últimos, qué porción de los ingresos familiares significaban esas remuneraciones, lo que sin duda era muy distinto en diversas épocas y regiones, como se reflexiona en el texto de Ramón Garrabou (2002). 
Sin embargo, la reconstrucción de las series de precios y salarios tiene una trascendencia difícil de soslayar y el avance, en este sentido, constituye un aporte de primer orden al conocimiento y explicación de un conjunto amplio de fenómenos históricos que exceden largamente el de la historia económica propiamente dicha.

En el caso rioplatense, y bonaerense específicamente, contamos con una serie de trabajos que estudiaron los precios durante el periodo colonial, especialmente el siglo XVIII con particular detenimiento en la etapa virreinal, a la vez que uno de estos autores, Lyman Johnson (1990), realizó un estudio muy importante sobre los salarios en este periodo, considerando una amplia gama de trabajadores urbanos y una única categoría de trabajador rural no especializado: el peón. Johnson pudo deflactar estos salarios tomando en cuenta una buena serie de precios y la confección de una canasta de consumo a partir de datos históricos.

Para la primera mitad del siglo XIX, sin embargo, el panorama es mucho más pobre. Existen series de precios de bienes (a veces mayoristas, a veces minoristas) pero carecemos de estudios que permitan elaborar una canasta razonable de precios y las series que lo habiliten. Todavía peor es el panorama sobre salarios, para los que tenemos apenas algunas series de empleados de gobierno relevados por F. Barba (1999) y datos, en general muy fragmentarios, de salarios de trabajadores rurales. También contamos con series de precios reconstruidos por Garavaglia (2004) de algunos bienes rurales básicos tomados al pie de estancia a partir de inventarios post mortem, a los que recurriremos para comparar con precios minoristas, así como con el estudio pionero de Amaral (1989) sobre el impacto de la inflación fiduciaria sobre algunos salarios y precios a partir de 1826, pero para pocos años y dos categorías de empleados escasamente representativos en esta etapa, el bancario y el maestro. Los datos de salarios rurales que utilizaremos junto a otros en este trabajo se encuentran de manera fragmentaria en Barba (1999) y más sistemática, aunque sólo para algunos años del periodo, en Gelman (1999).

\section{FUENTES Y MÉTODOS}

En este trabajo entonces vamos a analizar algunas series de salarios de Buenos Aires, tanto de empleados del Estado como de trabajadores privados.

Los primeros que hemos relevado son los salarios militares, para los que contamos con fuentes sistemáticas y continuadas a lo largo de un periodo prolongado, con suficientes datos para cada año y las distintas categorías. Para su análisis hemos elegido tres categorías que representan a la mayoría de los integrantes de las fuerzas militares, a la vez que permiten 
observar la evolución comparada de los salarios de los oficiales (en la figura del capitán), suboficiales de baja graduación (en la del cabo) y los soldados rasos, mayoría abrumadora de los miembros de las fuerzas; hemos dejado de lado la inclusión de oficiales de mayor graduación ya que su representatividad es minoritaria en la fuerza y en el asalariado, aunado a lo anterior, se debe contemplar el rango y el salario de cada uno, hecho que sería imposible reflejar sin contar que estos datos no influyen en el resultado final.

Tenemos datos para 1841 y 1861 sobre el peso relativo de los tres subgrupos de militares, los cuales indican que los soldados representan en ambos años cerca de 65\% de los empleados por las fuerzas armadas y el resto se reparte entre oficiales $(10.5 \%$ en la fecha más temprana y $14 \%$ en 1861) y suboficiales (25 y 21\% respectivamente) (Garavaglia, 2003). ${ }^{1}$

Es evidente que los salarios militares no son los únicos que paga el Estado, pero los castrenses durante el periodo bajo consideración eran de lejos el sector más numeroso mantenido con los dineros públicos. Según Juan Carlos Garavaglia (2003, 2011), los gastos militares oscilaron entre un mínimo de 53\% del gasto total del Estado hasta $81 \%$ entre 1824 y 1861 y, si bien los salarios no eran el único componente de ese gasto, los asalariados representaban siempre una amplia mayoría de los gastos incurridos por ese concepto. La cantidad de militares sostenidos por el Estado porteño en 1823,1841 y 1861 era de 3058 personas en la primera fecha $(88 \%$ del total pagado por el Estado), 7922 en $1841(83 \%)$ y 6584 (75\%) en la última fecha. Muy lejos del personal militar aparecían otras categorías vinculadas al control represivo de la población, como los policías y los serenos. Es decir, el lugar para el resto del personal del Estado era mínimo aunque creciente, sobre todo en la última de las fechas mencionadas (Garavaglia, 2003, 2011). Por lo tanto se puede afirmar, con pocas dudas, que los salarios militares expresan un porcentaje altísimo de los salarios estatales de Buenos Aires y estos, a su vez, un porcentaje elevado del total de asalariados de la sociedad.

Volviendo al ejemplo de 1841, la población total de la provincia era de 153000 habitantes, de los cuales los varones en edad laboral eran aproximadamente 52000 (Fuente, 1872), ${ }^{2}$ por lo que los militares podían constituir cerca de $15 \%$ de ese total (hasta $20 \%$ si se suman los miembros de las milicias movilizados ese año). Se debería agregar al sector femenino en la población económicamente activa, sin embargo, por lo que sabemos, era un sector muy restringido del mundo de los asalariados, en especial entre

\footnotetext{
${ }^{1}$ Los números de 1841 para oficiales, suboficiales y soldados son de 836, 1979 y 5107 , y en 1861 son de 914, 1350 y 4 160, respectivamente.

${ }^{2}$ Obtenido aplicando la proporción de varones entre 16 y 70 años del censo de 1869.
} 
los rurales, aunque es obvio que realizaban una parte central del trabajo en las explotaciones familiares y en las tareas domésticas.

Así, estos salarios son representativos de los que percibían los empleados del Estado, que a la vez eran un porcentaje muy alto de la población masculina adulta total y, por ende, un porcentaje todavía mayor del sector de los asalariados; de esa población masculina sólo una porción vivía de su salario, mientras un sector importante poseía medios de producción o administraba pequeños emprendimientos autónomos en el sector comercial y de servicios. En trabajos anteriores, Garavaglia (1999) y Gelman y Santilli (2006) han mostrado que una parte significativa, aunque difícil de mensurar, de los campesinos compartía parte de su tiempo laboral entre su propia explotación y el contrato con otros empresarios rurales.

Más difícil de resolver es el peso de estos salarios en los ingresos del militar y de su familia. Por un lado, sabemos que estos recibían sus vestimentas militares y raciones de alimentos para su subsistencia, de modo que el salario era sólo una parte de sus ingresos. Según datos globales, para 1841 y 1861 los gastos militares destinados a rancho y vestimenta sumaban una cifra aproximadamente igual a la destinada a salarios en la primera fecha y en la segunda, la relación se acerca a 60\% para los salarios y $40 \%$ para vestimenta y rancho. Las cifras para 1841 indican que se pagaban en salarios unos 5000000 de pesos corrientes y se gastaba en vestuario y rancho entre 3000000 y 2000 000, respectivamente. En la segunda fecha aumenta el peso relativo de los salarios, que alcanzan a más de 21000000 de pesos corrientes, frente a unos 12000000 en rancho y unos 2800000 en vestuario (Garavaglia, 2003).

Es muy posible que en los momentos en que el salario real disminuyera, a veces fuertemente por procesos inflacionarios, las raciones de alimentos y/o vestimenta que estos recibían cayeran mucho menos o no lo hicieran, compensando de esta manera parcialmente la reducción de sus niveles de vida. En este momento, resulta imposible determinar de qué manera se distribuía el rancho y la vestimenta en las distintas categorías de militares, por lo que no podemos incluir esa información en este estudio centrado en la desigualdad. ${ }^{3}$ Por otro lado sabemos que esos salarios monetarios eran una parte imprescindible del sostenimiento de la familia del

${ }^{3}$ El rancho era de 13 pesos en 1835, cuando el sueldo del soldado era de 20 pesos y el del capitán de 150. Archivo General de la Nación, Argentina, sala III 1.1.1. Esa suma era consignada en las listas como si fuera igual para las distintas jerarquías militares, lo que habría reducido un poco las distancias salariales. Sin embargo, no sabemos si esta anotación en las planillas correspondía a plata contante o a productos con ese valor y, más importante aún, si se trataba de entregas personales o era un prorrateo del gasto total en alimentación, seguramente diferenciado según la categoría. Lo mismo debía suceder con la vestimenta. Es por eso que no podemos incluir este dato en la suma salarial para estudiar la desigualdad. 
militar movilizado, que en este caso no tenía la compensación del alimento o la ropa provista por el Estado, de manera que ese dato resulta más significativo aún para este sector. ${ }^{4}$ Además, Fradkin (2010) y Rabinovich (2011) han revelado que el Estado no cumplía regularmente con los pagos de salarios de los militares, lo cual ocasionaba problemas en la subsistencia de sus familias y quizá no tanto en la propia del militar por el mantenimiento que realizaba directamente el Estado a través de la entrega del rancho (aunque a veces también este se demoraba) dando lugar a situaciones de apropiación directa de recursos sobre el terreno.

En cuanto a los salarios privados hemos podido reconstruir series bastante completas para el periodo de 1810-1850, con datos menos sistemáticos para la década de 1850 y 1860 . En este caso trabajamos con diversas remuneraciones rurales que consideramos representativas de la mayoría de los trabajadores asalariados: el peón común con paga mensual, el capataz con salario también mensual y el peón-jornalero con pago diario. En este último caso a los efectos de algunas comparaciones con las dos primeras categorías, consideramos que este jornalero podía trabajar un promedio de quince días al mes, lo que resulta una cifra arbitraria pero que supone que estos trabajadores, que ganaban sueldos diarios muy superiores al del peón mensual y aun al del capataz, no trabajaban todo el año. ${ }^{5}$ Incluso es posible que quince días al mes en promedio sea una cifra excesiva, pero no podemos decir mucho más sobre ello. En general se puede sostener que el jornalero, comparado con el peón mensualizado, representaba un sector de trabajo más especializado, con algún conocimiento o destreza que le permitía obtener un salario superior al del trabajador estable. Por ejemplo, en la etapa de predominio de la ganadería extensiva se requería este tipo de trabajador para tareas como la marcación y castración de animales o para la doma de caballos. ${ }^{6}$ Igualmente, eran trabajadores de este tipo los

${ }^{4}$ Hemos encontrado juicios en los que la esposa de un militar movilizado alega dramáticamente para no ser desalojada de la casa que habita de alquiler, cuya renta no puede pagar por encontrarse su marido movilizado y no recibir el dinero de su salario. Anzoategui, Petrona vs. Carlota Tejada Serrano. (1845). (Desalojo. A53, Tribunales). Archivo General de la Nación, Buenos Aires, Argentina.

${ }^{5}$ Podríamos hacer la operación inversa, de dividir el salario del peón y capataz mensual a un jornal diario, tomando por ejemplo como cantidad de días trabajados 25 al mes. Así lo hacen muchos estudios sobre salarios en el ámbito internacional. Sin embargo, para los efectos de comparar dicho salario mensual con el del jornalero sigue siendo tanto o más arbitrario como la decisión que hemos tomado, ya que al no saber cuántos días al mes y al año trabajaba el jornalero, resultan datos incomparables en cuanto a los ingresos y las condiciones de vida de estos tipos de trabajadores. También el trabajador mensualizado frecuentemente no trabajaba todo el mes por decisiones personales, procediendo el empleador a descontarle los días no trabajados.

${ }^{6}$ Así, entre muchos ejemplos, en una contabilidad se designa a estos trabajadores como capa toros, es decir, los que poseen la habilidad con el cuchillo de esterilizar a los toros. [Capa toros] Archivo General de la Nación, Tribunal Civil B-11, exp. 18, 1828, y Archivo General de la Nación, Bartolomé Sueldo y Gómez, Sucesión leg. 8184, 1862. 
que realizaban la cosecha y trillado del trigo o ciertas tareas especializadas con el ganado ovino, los que tendrán un peso creciente desde los años cuarenta y cincuenta del siglo XIX. Además, muchas veces este tipo de trabajador disponía de cierto capital productivo que le permitía desempeñar esa tarea (ya sea una tropilla de caballos propia para la yerra del vacuno, ciertas herramientas, etc.) y explicaba en parte el mayor salario relativo que ganaba. Pero a la vez encontramos que en situación de escasez relativa de trabajo, muchos peones, que normalmente se contrataban como mensualizados, buscaban -y lograban- contratarse como jornaleros para hacer las mismas tareas que antes realizaban con un salario menor; por esta misma razón, el empleador trataba de limitar al máximo este tipo de contrato, pero ello dependía de la fuerza de negociación de las partes en distintas coyunturas. Esta situación fue analizada por Gelman (1999) para las estancias de Juan Manuel de Rosas, quien en ciertos momentos de fuerte escasez de peones mensuales sólo conseguía jornaleros para las tareas más ordinarias de sus estancias.

Así pues, podemos afirmar que regularmente la demanda de jornaleros expresa la de una mano de obra más especializada que la del peón mensual. Lo mismo se puede decir en el caso del capataz, cuya principal habilidad es la de comandar a un grupo de peones. El peso de los trabajadores asalariados en el sector rural de Buenos Aires no es fácil de medir. Según los padrones disponibles para 1813 y 1815, entre los varones adultos que declaran una ocupación en el sector rural, los titulares de alguna explotación agraria (estancieros, labradores, criadores, hacendados) y en mucha menor medida de algún comercio (comerciantes y pulperos) suman una cifra muy similar a la que integran las categorías de trabajadores dependientes (peones, capataces, jornaleros, conchabados, más los esclavos que por estas fechas son casi la mitad de este grupo). ${ }^{7}$ Desde la libertad de vientres de 1813 y las dificultades crecientes del tráfico esclavo, este sector perdió peso rápidamente y se puede decir que ya en los años treinta resultaba una fracción muy minoritaria y en extinción de la población rural. Y aunque algunos propietarios ensayaron otros sistemas de trabajo coercitivo para remplazar al de la esclavitud, estos tuvieron poca vida y escasa importancia en Buenos Aires (Gelman, 1999). Para 1854 el peso de los trabajadores -ahora todos ellos libres- había crecido en relación con la fecha anterior siendo más numerosos que los titulares de explotaciones, pero los porcentajes no eran tan distantes. En la campaña, los titulares de explotaciones agrarias sumaban algo más de 30\% del total. A ello se deben

${ }^{7}$ Los titulares de explotaciones rurales y comerciales sumaban 6016 personas, los trabajadores libres 3 254, los esclavos 2714 y, finalmente, los criados 920 (Grupo de Investigación en Historia Rural Rioplatense, 2004). 
agregar los titulares de pequeños comercios, otros servicios y actividades secundarias. El resto estaba constituido por diversas categorías de trabajadores. En la ciudad, en 1855 los trabajadores y dependientes en general parecen haber sido un porcentaje mayor (Sábato y Romero, 1992).

No todos los titulares de explotaciones eran dueños de los medios de producción que utilizaban, una parte significativa producía en tanto arrendatarios, aparceros u otras categorías que recurrían al uso de medios de producción ajenos. Un problema muy difícil de discernir es el de los límites entre las distintas categorías ocupacionales que aparecen en los censos y padrones. Sabemos por algunos estudios de caso (Gelman 1999; Garavaglia, 1999) que muchas veces un peón que se desempeñaba como tal comenzaba una actividad simultánea como productor semiautónomo en tierras propias o del estanciero para el que trabajaba en relación de dependencia -es frecuente, por ejemplo, que los capataces estuvieran autorizados a criar algunos animales o a plantar algo en las tierras de su patrón-; parece claro que muchos pequeños propietarios que hemos podido seguir a través de padrones de riqueza, como los de la contribución directa, tenían un nivel tan escaso de medios propios que sin duda debían complementar los ingresos que ello les permitía con el trabajo asalariado, al menos temporal -y en esta situación podemos encontrar a muchos de los definidos como jornaleros. Podemos decir que las categorías de trabajadores asalariados que vamos a considerar representaban un porcentaje importante de todo el trabajo rural, aunque seguramente no alcanzaba en esta etapa a 50\% del total de la población económicamente activa.

Sabemos muy bien que el sector rural de propietarios de medios de producción, si bien crece a buen ritmo en toda la etapa considerada, lo hace siempre en menor medida que la población, de manera que el sector de no propietarios - potenciales oferentes de trabajo asalariado en el mercado- crece en términos relativos (Gelman y Santilli, 2011). Sin embargo, ello no nos indica cómo evolucionó el sector de pobladores que sin ser propietarios podían iniciar una explotación propia en tierras ajenas. Todo parece indicar que el sector asalariado tendió a crecer, no demasiado rápidamente, a lo largo del periodo bajo análisis, pero resulta imposible medir esto con alguna exactitud. Igualmente se plantea la cuestión del componente no salarial de los ingresos de estos trabajadores.

Tanto en el caso de los mensualizados como en el de los jornaleros, el propietario normalmente proveía el alimento durante el tiempo de la contrata; en el caso de los trabajadores por día, era frecuente que a los jornaleros se les proveyera también de algunos vicios como yerba, tabaco y aguardiente. De esta manera es posible suponer que la distancia entre el salario del jornalero y de los peones mensuales fuera algo mayor a la que indican sus salarios nominales, por la más abundante provisión de alimen- 
tos y vicios durante el tiempo de su contrata. Sin embargo, no estamos en condiciones de evaluar el peso de estos bienes en los ingresos del trabajador, aunque al igual que hemos señalado para el caso de los militares, ellos deberían desempeñar un papel muy importante especialmente en los momentos de caída brusca del poder de compra de los salarios monetarios por procesos inflacionarios. En todo caso, se puede suponer que, a diferencia del caso de los militares, a los trabajadores rurales no se les proveía de vestido, por lo tanto, el componente no salarial de su ingreso debía ser menor. ${ }^{8}$

No hemos podido construir series consistentes de salarios urbanos, por lo que los dejamos de lado. No obstante, a manera de hipótesis plausible, es difícil suponer que hubiera grandes distancias entre los salarios de los trabajadores urbanos y rurales, al menos en sus escalones más bajos y menos especializados, dada la gran articulación del mercado de trabajo entre ambos sectores.

Para una explicación de cómo construimos las series salariales, véase el anexo metodológico.

\section{LOS SALARIOS MILITARES}

Dada la importancia de las guerras y de la actividad militar en toda la primera mitad del siglo XIX debemos suponer, sin mucho margen de error, que los valores de los sueldos debieron ser altos. Como señalaron Halperin Donghi (1978a) y Lyman Johnson (1990), la etapa de extrema militarización (1806-1810), elevó la paga de los soldados a niveles altos respecto a la media de la sociedad. Pero ese nivel alcanzado en los últimos años del virreinato parece haberse estabilizado durante la primera década independiente (véase gráfica 1 ).

En la gráfica 1 se observa una importante distancia entre el salario del oficial, el de soldados y suboficiales durante la segunda década de 1800, distancia que se amplía luego por la subida de los salarios de los oficiales a mediados de la década de 1820 por encima del incremento percibido por los soldados y cabos. Luego se observa la profunda caída de todos los salarios en pesos fuertes que acompaña a la desvalorización del papel moneda desde $1826 .^{9}$ Inicialmente, esa caída es similar en las distintas categorías,

\footnotetext{
${ }^{8}$ Si fueran proporciones similares a las que gasta el Estado en los militares, se podría decir que los alimentos que recibía el trabajador rural podían constituir entre 20 y $30 \%$ de sus ingresos totales (excluyendo el peso de las vestimentas en los gastos militares según lo indicado anteriormente).

${ }^{9}$ En 1821 se creó en Buenos Aires una moneda sustituta del peso fuerte en plata, de libre convertibilidad, cuya paridad era uno a uno, y que estaba respaldada por los ingresos por gravá-
} 


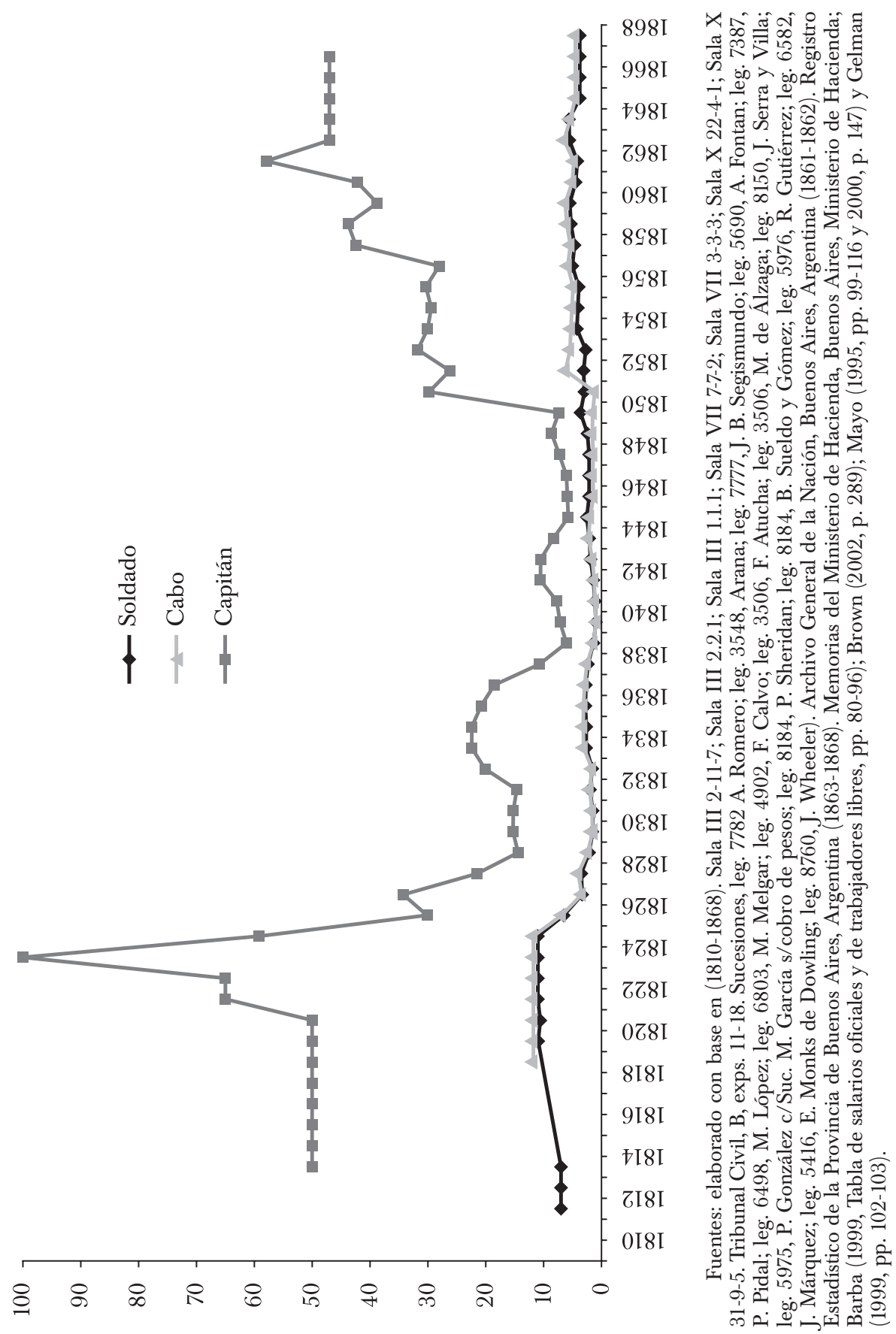


manteniéndose la gran distancia salarial de fines de los años veinte, pero a medida que avanzó la década de 1830 esa distancia disminuyó hasta alcanzar sus mínimos en los años cuarenta. Es muy notable también la falta de recuperación de esas remuneraciones en moneda fuerte, que si bien muestran un crecimiento en la primera mitad de los treinta -un momento de cierta estabilidad monetaria-, sufrirá otro retroceso fuerte entre 1838 y 1840, debido al proceso inflacionario que acompañó el bloqueo francés del puerto y la cuantiosa emisión monetaria. ${ }^{10}$ En consecuencia, durante el rosismo maduro, ${ }^{11}$ los valores salariales de soldados y oficiales están más cerca que nunca, a la vez que ambos están en sus mínimos de todo el periodo en términos de moneda fuerte.

Luego de 1852 la relación vuelve a cambiar; mientras los sueldos de los soldados se modificaban muy poco, los de los oficiales subían aceleradamente. Aquí se refleja palmariamente el salto del sueldo de los oficiales apenas producido el cambio de régimen político. La jerarquización de la segunda década, reforzada en los veinte, durante el rivadavianismo ${ }^{12}$ se lleva a cabo en esta oportunidad con firmeza; este fenómeno de diferenciación salarial postcaseros ya había sido señalado por Garavaglia (2003) comparando algunos salarios militares y estatales de 1841 y 1861 . Nuestra serie confirma esto y lo fecha con precisión en 1852, exactamente al caer Rosas del poder. En la gráfica 2 se observa el cociente entre el sueldo del capitán y el del soldado a lo largo de toda la etapa en estudio. Es difícil suponer, en dicha gráfica, una relación de causalidad entre procesos inflacionarios agudos por emisión monetaria y desigualdad salarial entre militares. Los periodos 1826-1829 o 1838-1841 de fuertes emisiones e inflación muestran tendencias distintas en cuanto a la distancia entre estos salarios (en la primera creciente, en la segunda declinante). Tampoco parece posible establecer una relación directa entre intensidad de los conflictos bélicos,

menes a las importaciones en la Aduana de Buenos Aires. Al comenzar la guerra con Brasil en 1825 se produjo el bloqueo al puerto de Buenos Aires, derrumbando así los ingresos fiscales que respaldaban al peso papel. El gobierno debió entonces decretar la inconvertibilidad de la moneda y comenzar a emitir papeles sin respaldo, provocando el primer gran proceso inflacionario de la historia rioplatense.

${ }^{10}$ Un incidente diplomático generó una controversia con el reino francés que motivó el bloqueo del puerto de Buenos Aires por parte de tal potencia, así como su intervención en las disputas entre sectores de las elites, conocidos como unitarios y federales, estos últimos en el gobierno.

${ }^{11}$ Denominamos rosismo maduro al lapso del gobierno de Juan Manuel de Rosas una vez vencida la resistencia interna y concluido el enfrentamiento con Francia, entre 1841 y su derrocamiento en 1852.

${ }^{12}$ Bernardino Rivadavia fue el ministro más activo del gobierno de Martín Rodríguez iniciado en 1820 en Buenos Aires, luego del fracaso de los intentos de la vieja capital virreinal por mantener unido y bajo su control el territorio de ese espacio colonial. En la segunda mitad de esa década el grupo conocido como los centralistas dominó un nuevo Congreso Constituyente e impuso a Rivadavia como presidente del país, pero debió renunciar en 1827 disolviéndose nuevamente el Estado unificado. 


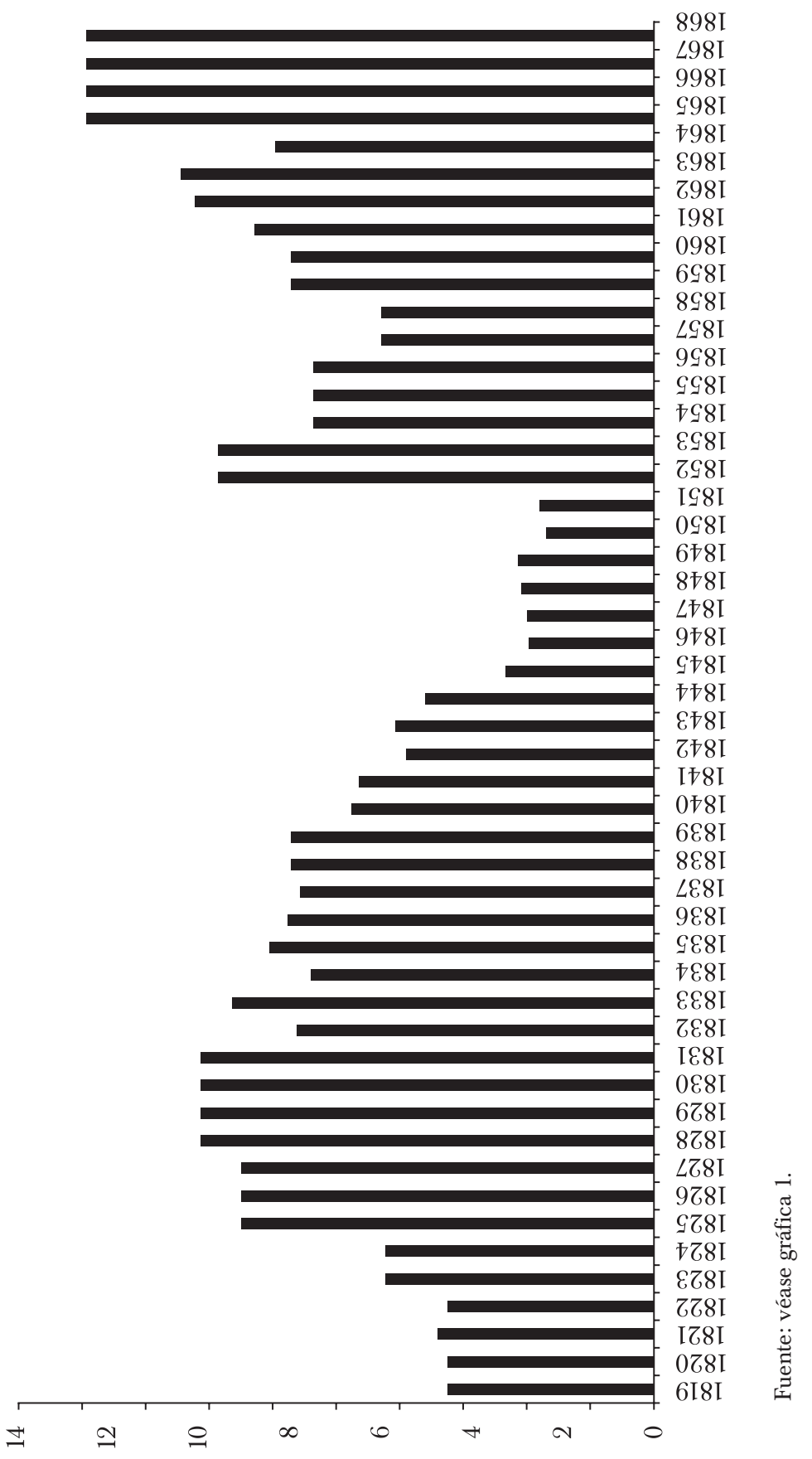


reclutamientos y desigualdad salarial. De hecho los mismos dos periodos inflacionarios recién mencionados coinciden con altísimos reclutamientos, en el primer caso por la guerra contra Brasil y en el segundo contra Francia y contra diversos enemigos internos, generándose procesos de desigualdad salarial distintos. Por lo tanto, dicha desigualdad tan fluctuante parece responder centralmente a las concepciones políticas de los gobernantes antes, durante y después de Rosas y a las características de los apoyos sociales con los que contaban o creían contar. Así, este aspecto de la desigualdad, nada desdeñable en una sociedad en la que la guerra intermitente implica la movilización militar de una parte muy considerable de la población, parece depender centralmente de la política.

\section{LOS SALARIOS RURALES}

Para el sector rural, como dijimos, vamos a analizar los salarios de los peones y de los capataces mensuales, así como el de los peones diarios o jornaleros. Como señalamos antes, esta última categoría se explica por necesidades puntuales de los ciclos ganaderos o agrícolas, por una mayor especialización en ciertas tareas que no eran permanentes y a veces también por la disponibilidad por parte del trabajador especializado de ciertos medios de producción para llevarlas a cabo. Pero a veces también era el resultado de las estrategias seguidas por los trabajadores -más raramente por los contratantes- para tener más flexibilidad laboral en situaciones de inestabilidad y cambio, así como para conseguir salarios que eran bastante más elevados que los del peón mensualizado o incluso que el del capataz. En estas series salariales nuestra información es bastante abundante, aunque presenta algunos claros que no podemos completar por ahora, sobre todo para los años cincuenta. Sin embargo se puede hablar de tendencias claras en el gran lapso en estudio. Veamos cómo se observan estos fenómenos con los valores ajustados en moneda fuerte (gráfica 3).

Los salarios de los trabajadores rurales se mueven más que los de los militares en la primera mitad del siglo. A un periodo de cierta estabilidad con algunas alzas y bajas hasta $1825^{13}$ le sucede en la segunda mitad de la década de 1820 un fuerte reajuste hacia abajo que tiene que ver con el movimiento inflacionario ya mentado, provocado por la declaración de inconvertibilidad del papel moneda y la cuantiosa emisión, aunque dicha

${ }^{13}$ Es difícil en el actual estado de conocimiento explicar cada uno de estos movimientos. Sin embargo, a manera de hipótesis a explorar se podría señalar la rápida y muy fuerte expansión del saladero a partir de 1816, con la consiguiente demanda de trabajo especializado que afecta seguramente también a muchas estancias que deben cambiar sus métodos de producción para satisfacer esa nueva demanda de carne. 


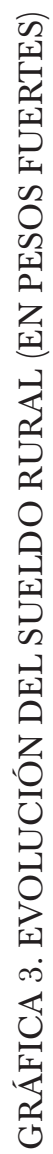

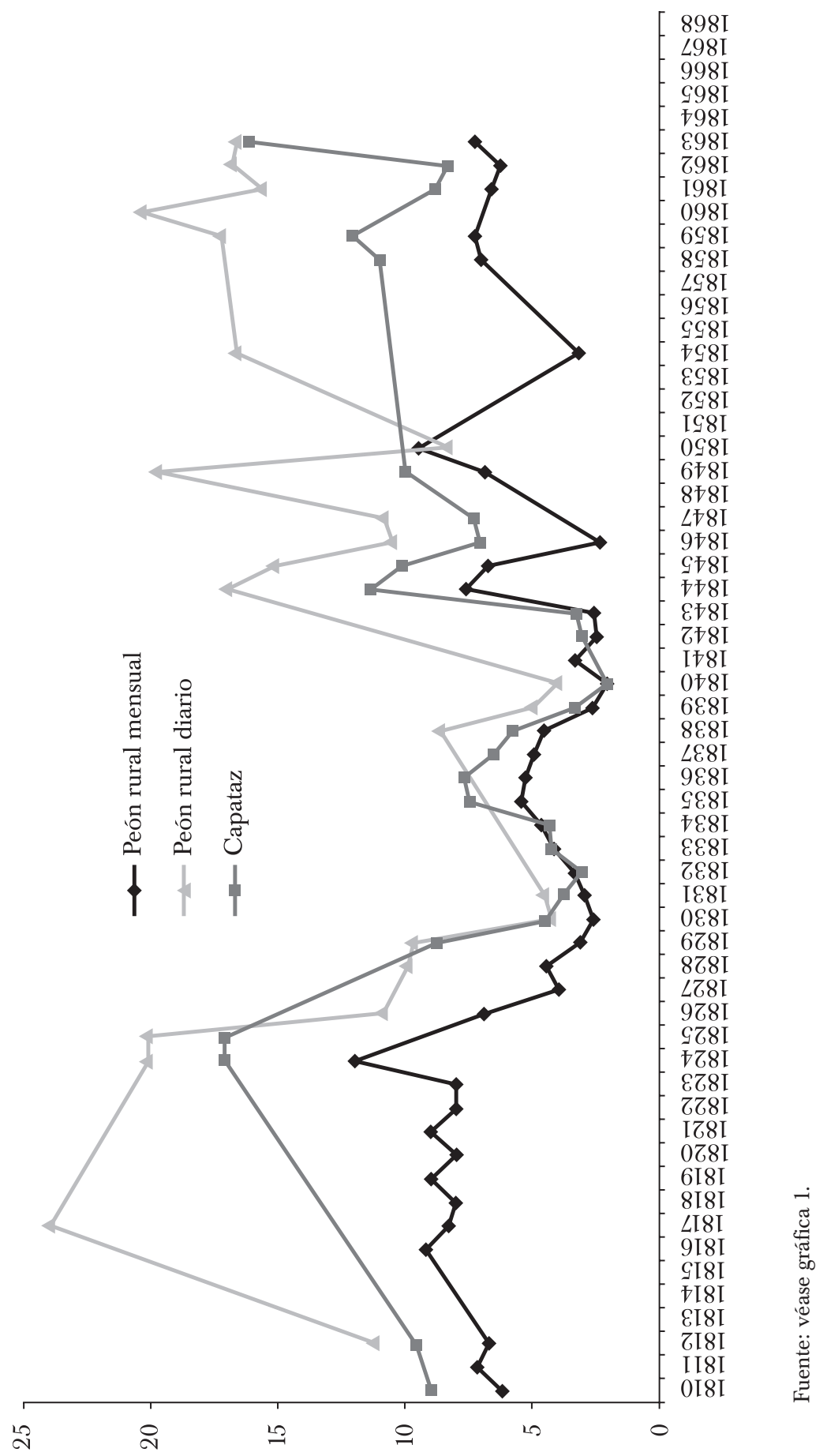


caída es relativamente menor a la de los militares, sobre todo los oficiales, y ello seguramente se debe a la escasez de trabajadores que provoca la guerra contra Brasil entre 1825 y 1828 y las numerosas levas militares. Nuevamente observamos mejoras significativas en los estables años de mediados de los años treinta (Halperin, 1978a; Irigoin, 2004), pero la caída se impone nuevamente en el crítico periodo de 1838 a 1840. Desde allí, a diferencia de lo observado en los salarios militares, la tendencia de los trabajadores rurales es al alza, aunque lo harán de manera diferenciada. Aquí se nota más claramente la respuesta de los actores del mercado ante esta nueva realidad, aumentando más el salario del peón diario que el del mensual. Es posible inferir que el propietario buscaba reducir a los empleados mensuales como forma de limitar sus riesgos ante la incertidumbre que genera la coyuntura de conflictos e inflación y contratar jornaleros por periodos cortos, como ya mencionamos; sin embargo, algunos estudios mostraron muy claramente que los salarios de los jornaleros resultaban muy altos para el estanciero, a la vez que la escasez relativa de peones permitía que estos buscaran, y en buena parte consiguieran, contratarse con jornales por día como forma de mejorar sus ingresos (Gelman, 1999). Pero a la vez se puede pensar que este incremento en el diferencial salarial, sobre todo del jornalero en relación con el peón -y en parte al capataz- es el producto de una creciente demanda de trabajo especializado y temporal en una economía que sabemos se estaba diversificando y complejizando con el desarrollo de actividades como la cría del ovino refinado, un sector agrícola todavía débil, pero más intensivo, y diversas actividades productivas urbanas y periurbanas, en los ya muchos pueblos de campaña. Parece un escenario parecido al pensado por Kuznets en relación con el desarrollo industrial temprano o al estudiado para la economía estadunidense de la misma época en la que la creciente demanda de trabajo especializado no es todavía acompañada por una oferta equivalente.

Lo cierto es que el salario diario no vuelve a acercarse al mensual, a pesar de que este último, sobre todo el del capataz, también tiende a subir. Además se nota una separación mayor entre la remuneración del capataz y la de los peones mensuales a partir de 1840, más notoria en las décadas de 1850 y 1860 , como un intento de jerarquizar la función, que se podría poner en paralelo con el movimiento similar de los salarios de los militares que describimos antes. La relación entre ambos salarios, peón y capataz, que rondaba históricamente en 1.5 veces llegó a tres veces en 1846, luego volvió casi a su nivel previo, pero llegó a más de dos veces en 1863. Parecería entonces que las condiciones del mercado de trabajo rural no han cambiado demasiado para estas dos categorías mensuales en este largo periodo, aunque sí lo hacen en relación con el trabajo por día del jornalero. La relación entre esta última remuneración y la del peón 
mensual, si bien conoce algunas oscilaciones a lo largo del periodo, tiende a crecer claramente desde los años cuarenta, pasando de algo más de 1.5 veces a picos de 4.5 y cinco.

Es decir, que podríamos hablar de la instalación desde mediados de la década de 1840 de un importante skill premium, donde seguramente se amplía el sector de trabajadores especializados que se contratan para diversas tareas por jornal, en lo que el ya fuerte desarrollo del ovino refinado tiene que haber sido determinante, junto a algunas actividades agrícolas y de servicios, a la vez que hay un cambio en las actividades ganaderas del vacuno con un salto importante en las exportaciones. De esta manera el mercado parece anticipar un movimiento de mayor desigualdad en los ingresos salariales, que desde la década de 1850, y por razones de índole política, adopta el Estado con sus empleados.

En cualquier caso, y aquí a diferencia de lo observado con los salarios militares, parece verificarse la incidencia de los periodos de fuerte devaluación monetaria e inflación en una mayor desigualdad entre los asalariados rurales. Tanto en los años que siguen a las emisiones de 1826, de manera menos clara luego de 1838 a 1839 y de nuevo durante los años que siguen al inicio del bloqueo anglo-francés de 1845 a 1848, la desigualdad salarial crece. Pareciera que los trabajadores especializados, en especial los jornaleros, logran en estos momentos de caída generalizada de los salarios reales negociar mejor sus condiciones de trabajo que los no especializados. Por otro lado, también pueden incidir los fuertes reclutamientos militares de estos años, con la consiguiente escasez de trabajadores, que favorece que los pocos disponibles en el mercado negocien mejor sus condiciones de trabajo y consigan en muchos casos emplearse como jornaleros con salarios más elevados. Sin embargo, más allá de estas coyunturas más o menos puntuales, nos parece percibir un movimiento de más amplio alcance, como dijimos, desde los primeros años cuarenta, que coincide con cambios importantes en la economía agraria bonaerense, que comienza a demandar mayor mano de obra especializada que en la etapa previa de dominio excluyente de la ganadería vacuna extensiva (véase gráfica 4).

\section{LA EVOLUCIÓN DE LOS SALARIOS DE LA MANO DE OBRA NO CALIFICADA}

Algunas observaciones específicas pueden hacerse al separar la mano de obra calificada (capataces, jornaleros y oficiales) de la no calificada, tanto rural como militar (peones, cabos y soldados). En la gráfica 5 puede percibirse su evolución.

Hasta 1825 aproximadamente, los salarios de los soldados eran mayores que los de los peones rurales, hecho que muestra cuáles eran las prioridades 

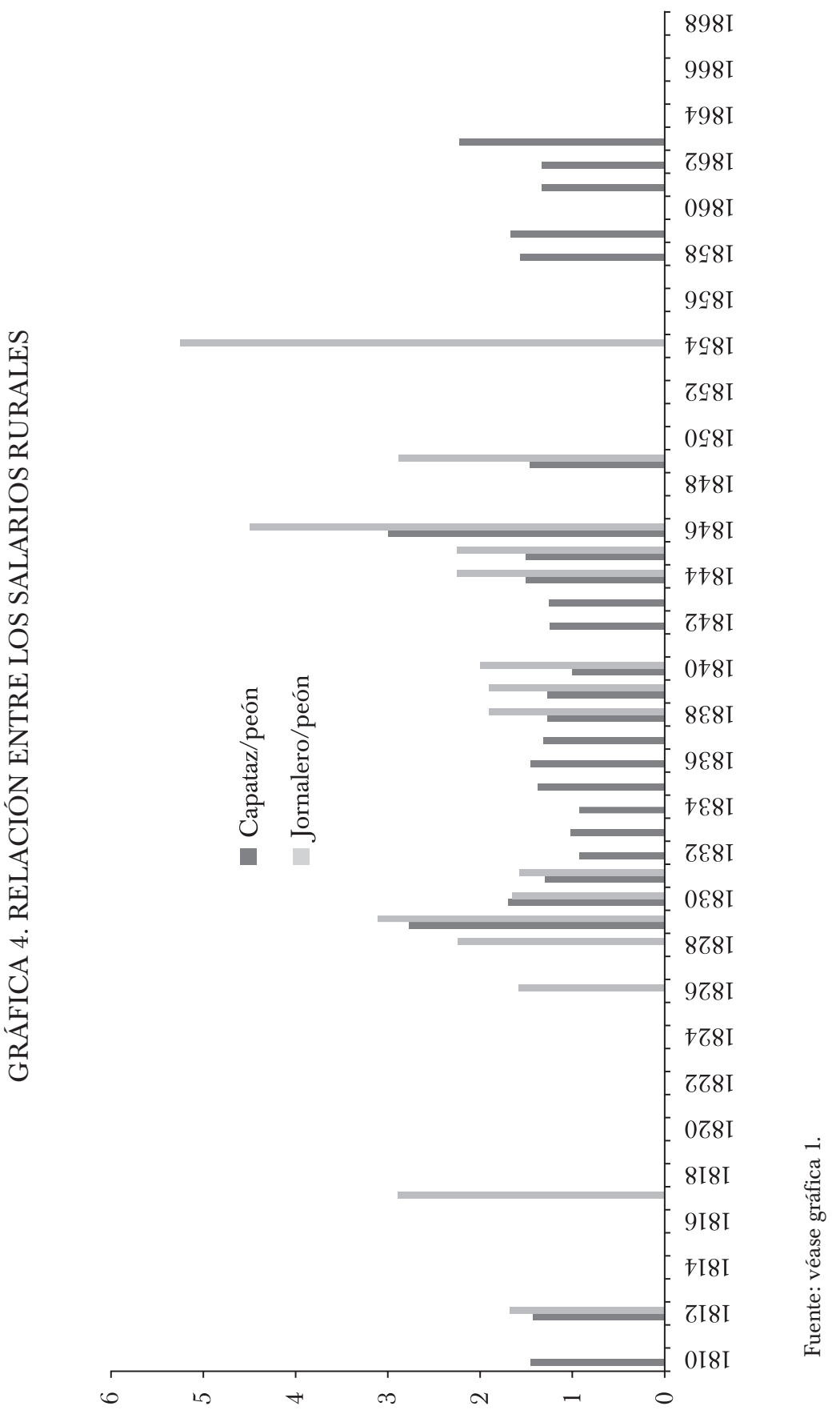

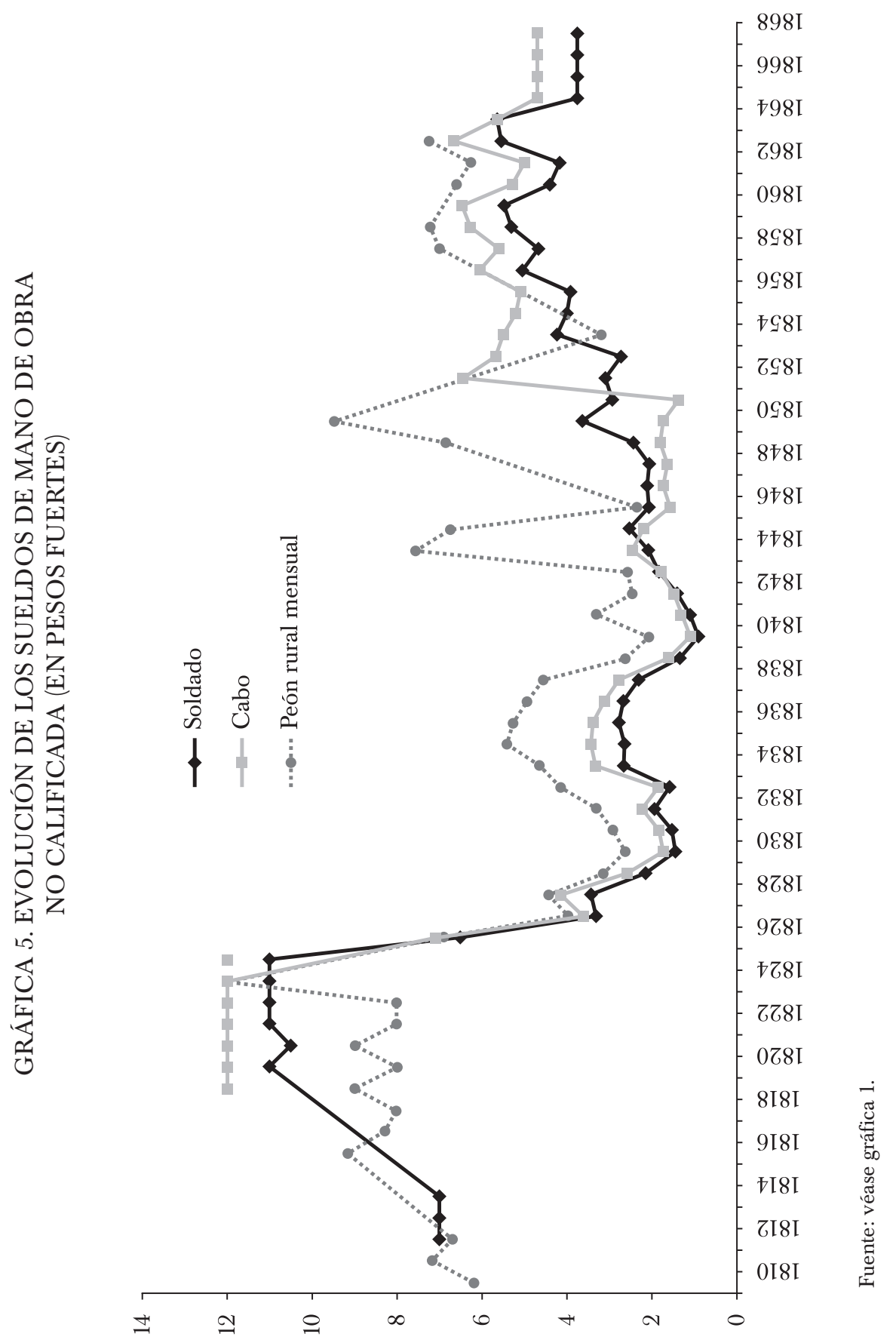
de la sociedad de la época; recién salidos de las guerras de independencia e ingresando en el conflicto con Brasil, los requerimientos de carne de cañón para los conflictos bélicos se ubicaban por encima de los relacionados con las actividades rurales, que hasta ese momento no parecen ser las dinamizadoras de la economía. También puede notarse una leve superioridad del suboficial respecto al soldado raso, como espejo de cierta jerarquía en las funciones. El aluvión inflacionario borrará esas diferencias equilibrando hacia abajo todos los valores. Pero inmediatamente superado ese episodio, la primera remuneración en levantarse fue la correspondiente a los asalariados rurales, que van a sacarle, hacia mediados de la década de 1830, una ventaja importante a sus pares del ejército. Esa diferencia se va a mantener a pesar de los vaivenes inflacionarios de finales del decenio y principios del siguiente. En la segunda mitad de los años cuarenta las distancias eran mayores, pero con importantes efectos de dientes de sierra en la curva. A partir de 1852 se nota, como con los oficiales, un aumento de los salarios militares que casi equilibran la relación con los peones, notándose nuevamente cierto grado de jerarquización entre suboficiales y tropa.

De modo que podemos interpretar diferentes situaciones en el movimiento de los salarios de la mano de obra no calificada. En principio, una superioridad de los valores de los soldados, de conformidad con lo señalado por Johnson (1990) y Halperin (1978), entre otros, para el periodo de máxima militarización de la sociedad. Luego del fin de las guerras y del proceso inflacionario, se observa un aumento de los salarios rurales coincidiendo con la expansión ganadera de tipo extensiva, cuya necesidad de mano de obra no calificada predominaba. Pero hacia el final del periodo puede notarse una jerarquización de las funciones militares, sobre todo de los suboficiales, así como un estancamiento del valor de los sueldos de los peones, coincidente con lo observado anteriormente sobre el escaso dinamismo en esta etapa de la demanda de mano de obra poco calificada en relación con la oferta. Sea como sea, los salarios más bajos de esta sociedad, los que recibía la mayoría de la población asalariada, se siguen muy de cerca entre sí y, como se observa en la gráfica 5, están fuertemente afectados en su relación con la moneda fuerte por los shocks inflacionarios, especialmente entre 1826 y 1829 y entre 1838 y 1842.

\section{CONCLUSiOnes}

\section{La desigualdad entre 1810 y 1870 a través de los salarios}

En este trabajo hemos analizado varias series de salarios que nos han permitido ver con claridad la evolución en los niveles de ingreso relativos de 
algunas categorías de trabajadores especializados y no especializados de la provincia, tanto de sus empleados estatales, como de los trabajadores rurales. Con ello, pudimos apreciar la evolución en las distancias entre las distintas categorías de trabajadores para evaluar algunos aspectos sobre la evolución de la desigualdad en la región, los efectos en la misma de los shocks inflacionarios, de las guerras, de los cambios económicos y políticos, así como proponer algunas hipótesis que deberán ser estudiadas con mayor detalle y más información para la segunda mitad del siglo XIX, sobre lo que la literatura denomina el skill premium, la relación entre el trabajo calificado y el que no lo es.

Veamos en la gráfica 6 de manera sintética las principales relaciones entre los salarios de los trabajadores calificados y los no calificados que hemos revisado a lo largo del trabajo.

Tanto entre los militares, como entre los trabajadores rurales, aparecen ciclos bastante claros en este sentido. En los primeros años que siguen a la revolución independentista, y en especial en los años veinte, encontramos niveles relativamente altos de desigualdad salarial y en crecimiento. Esta tendencia es más notable entre los militares, pero se percibe también entre los asalariados rurales. Cuando todos los salarios se derrumban en pesos fuertes hacia finales de esta década la distancia en general se mantiene, inclusive con algo de crecimiento. Pareciera que en esta etapa inicial de fuertísima inflación los salarios mayores o más especializados se defienden algo mejor que los no especializados y bajos. Luego comienza un achatamiento general de la desigualdad en los treinta que se agudiza en los cuarenta, pero sólo para los militares. El segundo golpe inflacionario fuerte de finales de los años treinta parece mostrar algo parecido al anterior, aunque más moderadamente: los salarios altos se defienden un poco mejor, aumentando mínimamente el skill premium. Esto es notable en los salarios de los jornaleros en relación con los peones mensuales y parece expresar esencialmente una mayor capacidad de negociación de sus salarios en un momento de aguda escasez de trabajadores y fuertes alteraciones en el mercado.

En la segunda mitad de esta década encontramos dos procesos bastante diferenciados entre los militares y los trabajadores rurales: mientras estos últimos inician una rápida recuperación de los salarios en pesos fuertes, y junto a ello un proceso de creciente desigualdad especialmente a favor de los jornaleros diarios, los salarios militares siguen deprimidos y en sus niveles más bajos de desigualdad de todo el periodo bajo estudio. Pero la desigualdad entre los militares se acrecienta muy radicalmente a la caída del gobierno de Rosas en 1852 para seguir acentuándose, con alguna fluctuación, en los años siguientes. 

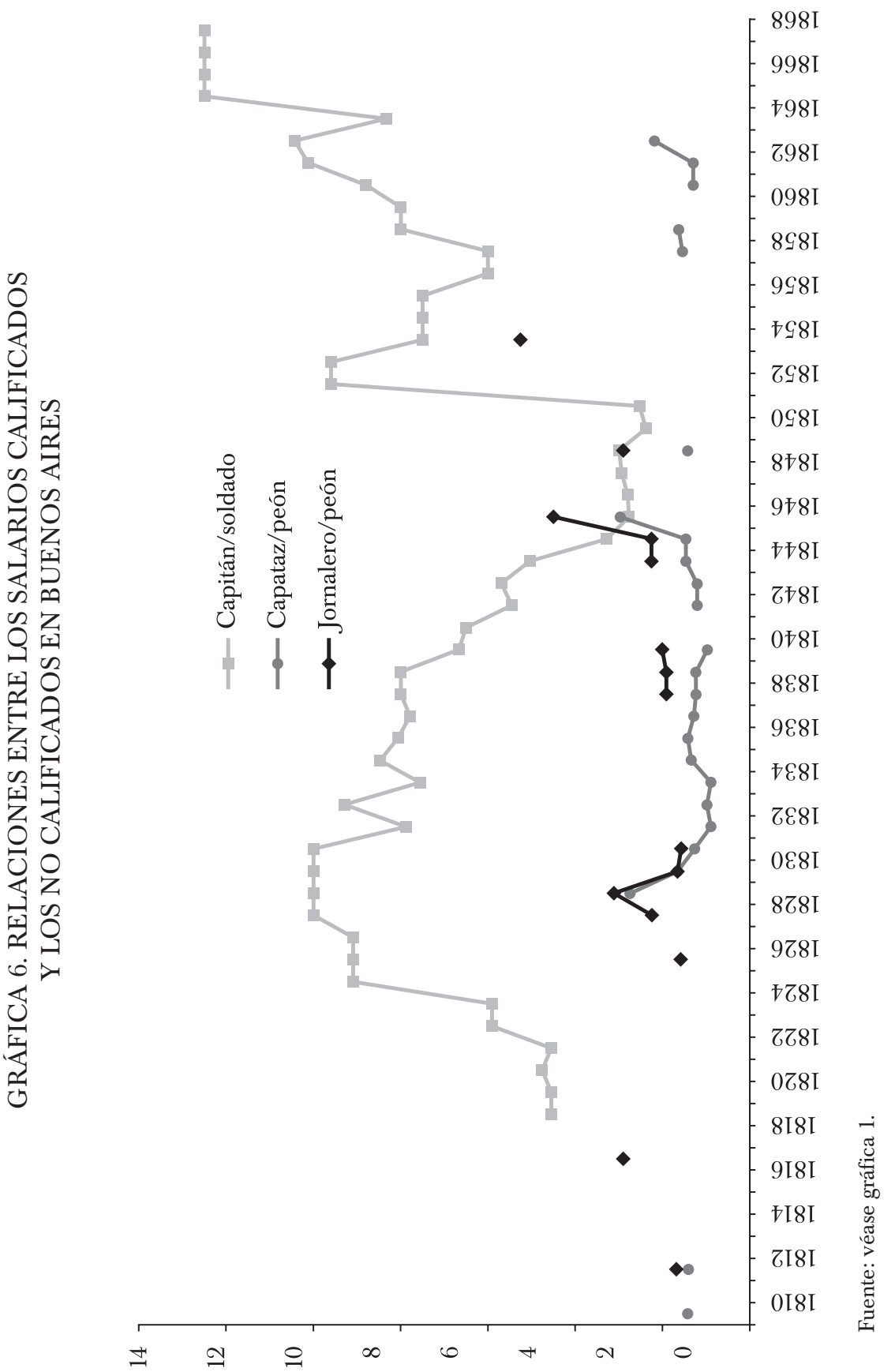
Entonces podemos hablar de algunos fenómenos que parecen estar afectando los niveles de desigualdad salarial en todas las categorías, junto a otros fenómenos bastante diferenciados entre los trabajadores dependientes del Estado y los privados, representados en este trabajo por los rurales, aunque suponemos que debió pasar algo similar con los trabajadores particulares de la ciudad, quienes muchas veces circulaban entre uno y otro sector del mercado de trabajo.

Los momentos de fuerte inflación parecen actuar de manera similar en todos los salarios. Bajan mucho todos ellos medidos en moneda fuerte, pero los salarios más altos, los especializados, se defienden en general algo mejor, aumentando de esta manera la desigualdad. Es decir que, al menos en el caso que estamos estudiando, el alza fuerte y repentina de los precios afecta de manera destacada a los asalariados más humildes, los que realizan tareas no especializadas.

Sin embargo hay algunos cambios importantes en la desigualdad que son diferentes entre los estatales y los rurales. Entre los primeros notamos dos periodos de alta desigualdad o desigualdad creciente: la década del veinte es la primera, especialmente en su segunda mitad, coincidiendo con el despliegue del programa de corte liberal rivadaviano, la guerra contra Brasil y la gran devaluación monetaria seguida de alta inflación. Los tres fenómenos parecen coincidir en este periodo para provocar un incremento fuerte y sostenido de la desigualdad salarial que incluye a los primeros años del gobierno rosista. Luego tenemos un largo periodo de disminución progresiva de la desigualdad en los salarios militares que se superpone con gran parte del gobierno de Rosas y llega a su mínimo en la segunda mitad de los años cuarenta -es de destacar aquí que un nuevo brote inflacionario a mediados de esta década con la guerra franco-inglesa no tiene efectos en la desigualdad salarial de los militares. $\mathrm{Y}$ al final, un periodo prolongado de creciente desigualdad salarial que arranca de manera brutal a la caída del gobernador Rosas y que se debe explicar casi totalmente por razones de índole política. De igual manera, en la diferencia salarial entre militares parece incidir el desarrollo de guerras prolongadas que requirieron niveles de reclutamiento y movilización muy elevados. Eso se nota en la guerra contra Brasil (1825-1828) y con la de la Triple Alianza que arranca en $1865 .{ }^{14}$ Sin embargo, este argumento no es válido para las grandes guerras que enfrentó el rosismo, en los que la desigualdad salarial entre militares siguió en declive.

En el caso de los trabajadores rurales hay algunas diferencias importantes. Entre estas, las distancias entre las categorías analizadas nunca son

\footnotetext{
${ }^{14}$ Se denomina así al conflicto bélico que protagonizaron Argentina, Brasil y Uruguay contra Paraguay, entre 1865 y 1870, y que concluyó con la derrota de esta última nación.
} 
tan grandes como la que hay entre el capitán y el soldado. Es verdad que quizá elegimos en este último caso categorías demasiado alejadas; pero más allá de eso, lo más importante es la evolución. En este sentido podemos decir que los ciclos son menos claros y continuos que en el caso de los salarios estatales, seguramente porque el mercado -muy fluctuante- actúa más rápida y fuertemente en estos trabajadores que en los que dependen del Estado. No parece nada extraño que así sea. Los procesos inflacionarios, como dijimos antes, parecen actuar en todos los casos en detrimento de los trabajadores menos calificados -aunque obviamente todos los trabajadores pierden en estas circunstancias-, probablemente lo más notable es la tendencia que parece esbozarse a partir de mediados de los años cuarenta en el sentido de instalarse una desigualdad salarial en niveles bastante más altos que en todo el periodo previo.

Aunque esto debe seguir siendo estudiado con más datos, y para un periodo más prolongado, parece indicar, el inicio de un proceso interesante de crecimiento económico de nuevo tipo, con una demanda de trabajo especializada más abultada, que todavía no es correspondida con una oferta equivalente, generando así este fenómeno más clásico de skill premium en etapas iniciales de intensificación económica.

De esta manera nuestro análisis de la economía de Buenos Aires parece apuntalar este modelo clásico - ¿a la Kuznets?-, aunque para una economía que no es industrial sino agraria, pero con un cambio en el patrón productivo bastante claro, al pasar de una economía de tipo extensivo a otra de tipo intensivo. Aunque esto requiere todavía de más investigación y análisis, es posible sostener a manera de hipótesis plausible que el tipo nuevo de crecimiento económico desde los años cuarenta y cincuenta está generando una mayor demanda de trabajo especializado que el mercado de trabajo todavía no está en condiciones de satisfacer plenamente, ocasionando ese incremento en el diferencial salarial a su favor, y con ello aumentando los niveles de desigualdad económica. Esta creciente desigualdad, por otro lado, ha sido comprobada en otro nivel, en el de la distribución de la riqueza inmueble a la que acceden porciones cada vez menores de una población que crece raudamente en todo el periodo (Gelman y Santilli, 2011). Con certeza, la combinación de un crecimiento demográfico acelerado, que excede en términos relativos el acceso a la propiedad de la tierra, favorece una creciente oferta de trabajo asalariado no calificado, cuando pareciera estar creciendo la demanda de trabajo especializado con mayor rapidez.

Cuando figura un solo registro de sueldos de militares significa que lo hemos tomado de registros bibliográficos o de planillas en las que el mismo valor se repetía para todos los involucrados. En cambio, cuando los registros son más numerosos es porque no hemos encontrado un valor 
único para esa categoría porque ha variado durante el periodo en observación o porque, dependiendo del lugar de asentamiento, el valor difería. Entre los rurales, al tratarse de contratos privados, los valores varían más que en el caso de los militares, por lo que decidimos tomarlos en todos los casos respetando, además, la periodicidad y el tiempo total del contrato o lapso contratado. En los casos en los que aparece consignado un solo registro, en realidad se trata de promedios de muchos datos anuales establecidos por los autores de los que tomamos esa información. En general esta información de los salarios rurales procede de contabilidades privadas que llevaban administradores de algunas grandes estancias consignando en cuadernos de peones los nombres, tipo de trabajo, la cantidad de tiempo y los salarios pagados. Es el caso de los salarios diarios que parecen disminuidos en cantidad de registros en comparación con los fijos (Barba, 1999; Gelman, 1999).

En los casos en que tenemos diversos valores para un mismo año, hemos promediado los mismos para obtener un precio que pueda considerarse generalizable. Además, como hemos respetado la cantidad de veces que se repiten dentro de cada año, es decir, si la misma persona aparece diez veces en el año hemos asignado un registro por cada vez, el promedio se convierte en ponderado por la cantidad de veces que aparece cada registro. Como dijimos antes, el promedio anual del peón diario lo hemos multiplicado por quince, considerando que esos son los días que el sujeto trabajaba en un mes.

En los cuadros 2 y 3 se muestra el salario promedio anual de los datos obtenidos, así como la relación entre las categorías extremas. 
108 Jorge Gelman y Daniel Santilli

ANEXo METODOLÓGICO. CONSTRUCCIÓN DE LAS SERIES SALARIALES

CUADRO 1. CANTIDAD DE REGISTROS POR TIPO

\begin{tabular}{|c|c|c|c|c|c|c|c|}
\hline$A \tilde{n} o$ & Soldado & Cabo & Capitán & Capataz & $\begin{array}{l}\text { Peón } \\
\text { rural }\end{array}$ & $\begin{array}{l}\text { Peón } \\
\text { diario }\end{array}$ & Total \\
\hline 1810 & - & - & - & 8 & 169 & - & 177 \\
\hline 1811 & - & - & - & - & 46 & - & 46 \\
\hline 1812 & 1 & - & - & 10 & 238 & 1 & 250 \\
\hline 1813 & 1 & - & - & - & - & - & 1 \\
\hline 1814 & 1 & - & - & - & - & - & 1 \\
\hline 1815 & - & - & 1 & - & - & - & 1 \\
\hline 1816 & - & - & 1 & - & 18 & - & 19 \\
\hline 1817 & - & - & 1 & - & 28 & 1 & 30 \\
\hline 1818 & - & - & 1 & - & 6 & - & 7 \\
\hline 1819 & 1 & 1 & 1 & - & 8 & - & 11 \\
\hline 1820 & 1 & 1 & 1 & - & 12 & - & 15 \\
\hline 1821 & 2 & 3 & 1 & 1 & 12 & - & 19 \\
\hline 1822 & 1 & 1 & 1 & - & 12 & - & 15 \\
\hline 1823 & 1 & 1 & 1 & - & 12 & - & 15 \\
\hline 1824 & 1 & 1 & 1 & - & 6 & - & 9 \\
\hline 1825 & 1 & 1 & 1 & - & - & - & 3 \\
\hline 1826 & 1 & 1 & 1 & - & 7 & 3 & 13 \\
\hline 1827 & 1 & 1 & 1 & - & 7 & 3 & 13 \\
\hline 1828 & 15 & 11 & 1 & - & 17 & 3 & 47 \\
\hline 1829 & 1 & 1 & 1 & 2 & 14 & 3 & 22 \\
\hline 1830 & 1 & 1 & 1 & 22 & 314 & 6 & 345 \\
\hline 1831 & 1 & 1 & 1 & 20 & 117 & 6 & 146 \\
\hline 1832 & 27 & 26 & 17 & 24 & 72 & - & 166 \\
\hline 1833 & 25 & 13 & 27 & 10 & 69 & - & 144 \\
\hline 1834 & 19 & 10 & 14 & 2 & 25 & - & 70 \\
\hline 1835 & 11 & 8 & 11 & 15 & 73 & - & 118 \\
\hline 1836 & 14 & 12 & 12 & 21 & 57 & - & 116 \\
\hline 1837 & 22 & 13 & 13 & 30 & 89 & - & 167 \\
\hline 1838 & 2 & 1 & 2 & 65 & 275 & 1 & 346 \\
\hline 1839 & 1 & 1 & 1 & 100 & 307 & 1 & 411 \\
\hline 1840 & 3 & 3 & 3 & 5 & 7 & 1 & 22 \\
\hline 1841 & 4 & 4 & 4 & - & 1 & - & 13 \\
\hline 1842 & 13 & 12 & 12 & 26 & 77 & - & 140 \\
\hline 1843 & 18 & 12 & 20 & 104 & 228 & - & 382 \\
\hline 1844 & 16 & 17 & 14 & 95 & 148 & 1 & 291 \\
\hline
\end{tabular}




\begin{tabular}{|c|c|c|c|c|c|c|c|}
\hline$A \tilde{n} o$ & Soldado & Cabo & Capitán & Capataz & $\begin{array}{l}\text { Peón } \\
\text { rural }\end{array}$ & $\begin{array}{l}\text { Peón } \\
\text { diario }\end{array}$ & Total \\
\hline 1845 & 26 & 24 & 13 & 74 & 153 & 1 & 291 \\
\hline 1846 & 50 & 47 & 20 & 5 & 3 & 1 & 126 \\
\hline 1847 & 47 & 45 & 19 & 2 & - & 1 & 114 \\
\hline 1848 & 62 & 52 & 13 & - & - & & 127 \\
\hline 1849 & 46 & 34 & 9 & 12 & 37 & 8 & 146 \\
\hline 1850 & 83 & 37 & 12 & - & 4 & 44 & 180 \\
\hline 1851 & 29 & 10 & 4 & - & - & - & 43 \\
\hline 1852 & 1 & 1 & 1 & - & - & - & 3 \\
\hline 1853 & 1 & 1 & 1 & - & - & - & 3 \\
\hline 1854 & 1 & 1 & 1 & - & 1 & 41 & 45 \\
\hline 1855 & 1 & 1 & 1 & - & - & - & 3 \\
\hline 1856 & 1 & 1 & 1 & - & - & - & 3 \\
\hline 1857 & 1 & 1 & 1 & - & - & - & 3 \\
\hline 1858 & 1 & 1 & 1 & 17 & 24 & - & 44 \\
\hline 1859 & 1 & 1 & 1 & 12 & 25 & 111 & 151 \\
\hline 1860 & 1 & 1 & 1 & - & - & 56 & 59 \\
\hline 1861 & 1 & 1 & 1 & 8 & 8 & 161 & 180 \\
\hline 1862 & 1 & 1 & 1 & 5 & 5 & 60 & 73 \\
\hline 1863 & 1 & 1 & 1 & 14 & 10 & 7 & 34 \\
\hline 1864 & 1 & 1 & 1 & - & - & - & 3 \\
\hline 1865 & 1 & 1 & 1 & - & - & - & 3 \\
\hline 1866 & 1 & 1 & 1 & - & - & - & 3 \\
\hline 1867 & 1 & 1 & 1 & - & - & - & 3 \\
\hline 1868 & 1 & 1 & 1 & - & - & - & 3 \\
\hline Total & 563 & 423 & 270 & 691 & 2236 & 519 & 4702 \\
\hline
\end{tabular}

Fuente: véase gráfica 1.

CUADRO 2. SUELDOS DE MILITARES (EN PESOS CORRIENTES)

\begin{tabular}{ccccc}
\hline Año & Soldado & Cabo & Capitán & $\begin{array}{c}\text { Relación } \\
\text { capitán/soldado }\end{array}$ \\
1810 & - & - & - & - \\
1811 & - & - & - & - \\
1812 & 7 & - & - & - \\
1813 & 7 & - & - & - \\
1814 & 7 & - & - & -
\end{tabular}




\begin{tabular}{|c|c|c|c|c|}
\hline$A \tilde{n} o$ & Soldado & Cabo & Capitán & $\begin{array}{c}\text { Relación } \\
\text { capitán/soldado }\end{array}$ \\
\hline 1815 & - & - & 50 & - \\
\hline 1816 & - & - & 50 & - \\
\hline 1817 & - & - & 50 & - \\
\hline 1818 & - & - & 50 & - \\
\hline 1819 & 11 & 12 & 50 & 4.55 \\
\hline 1820 & 11 & 12 & 50 & 4.55 \\
\hline 1821 & 10.50 & 12 & 50 & 4.76 \\
\hline 1822 & 11 & 12 & 50 & 4.55 \\
\hline 1823 & 11 & 12 & 65 & 5.91 \\
\hline 1824 & 11 & 12 & 65 & 5.91 \\
\hline 1825 & 11 & 12 & 100 & 9.09 \\
\hline 1826 & 11 & 12 & 100 & 9.09 \\
\hline 1827 & 11 & 12 & 100 & 9.09 \\
\hline 1828 & 10 & 12.11 & 100 & 10 \\
\hline 1829 & 10 & 12 & 100 & 10 \\
\hline 1830 & 10 & 12 & 100 & 10 \\
\hline 1831 & 10 & 12 & 100 & 10 \\
\hline 1832 & 12.70 & 14.62 & 100 & 7.87 \\
\hline 1833 & 11.16 & 13.08 & 103.70 & 9.29 \\
\hline 1834 & 18.53 & 23.20 & 140 & 7.56 \\
\hline 1835 & 18.45 & 24 & 156.36 & 8.47 \\
\hline 1836 & 19.64 & 24 & 158.33 & 8.06 \\
\hline 1837 & 20.55 & 24 & 160 & 7.79 \\
\hline 1838 & 20 & 24 & 160 & 8 \\
\hline 1839 & 20 & 24 & 160 & 8 \\
\hline 1840 & 20 & 24 & 133.33 & 6.67 \\
\hline 1841 & 20 & 24 & 130 & 6.50 \\
\hline 1842 & 23.08 & 24.17 & 125.83 & 5.45 \\
\hline 1843 & 28.89 & 28 & 164.50 & 5.69 \\
\hline 1844 & 27.50 & 32.59 & 138.57 & 5.04 \\
\hline 1845 & 37.54 & 32.67 & 123.08 & 3.28 \\
\hline 1846 & 44.16 & 33.53 & 122 & 2.76 \\
\hline 1847 & 43.64 & 35.87 & 122.11 & 2.80 \\
\hline 1848 & 41.95 & 33.19 & 123.08 & 2.93 \\
\hline 1849 & 42.67 & 31.59 & 127.78 & 2.99 \\
\hline 1850 & 51.87 & 24.76 & 123.33 & 2.38 \\
\hline 1851 & 51.52 & 24.20 & 130 & 2.52 \\
\hline 1852 & 50 & 104 & 480 & 9.60 \\
\hline 1853 & 50 & 104 & 480 & 9.60 \\
\hline
\end{tabular}




\begin{tabular}{ccccc} 
Año & Soldado & Cabo & Capitán & $\begin{array}{c}\text { Relación } \\
\text { capitán/soldado }\end{array}$ \\
1854 & 80 & 104 & 600 & 7.50 \\
1855 & 80 & 104 & 600 & 7.50 \\
1856 & 80 & 104 & 600 & 7.50 \\
1857 & 100 & 120 & 600 & 6 \\
1858 & 100 & 120 & 600 & 6 \\
1859 & 110 & 130 & 880 & 8 \\
1860 & 110 & 130 & 880 & 8 \\
1861 & 100 & 120 & 880 & 8.80 \\
1862 & 100 & 120 & 1012 & 10.12 \\
1863 & 150 & 180 & 1565 & 8.43 \\
1864 & 162.49 & 162.49 & 1354.07 & 12.50 \\
1865 & 103.06 & 128.83 & 1288.27 & 12.50 \\
1866 & 91.56 & 114.45 & 1144.45 & 12.50 \\
1867 & 93.77 & 117.22 & 1172.18 & 12.50 \\
1868 & 94 & 117.50 & 1175 & \\
\hline
\end{tabular}

Fuente: véase gráfica 1.

\section{CUADRO 3. SUELDOS RURALES (EN PESOS CORRIENTES)}

\begin{tabular}{cccccc}
\hline & $\begin{array}{c}\text { Peón rural } \\
\text { mensual }\end{array}$ & $\begin{array}{c}\text { Peón rural } \\
\text { diario }\end{array}$ & Capataz & Capataz) & Jornalerol \\
Año & Col. 1 & Col. 2 & Col. 3 & peón & peón \\
1810 & 6.20 & - & 9 & 1.45 & - \\
1811 & 7.17 & - & - & - & - \\
1812 & 6.70 & 11.25 & 9.55 & 1.43 & 1.68 \\
1813 & - & - & - & - & - \\
1814 & - & - & - & - & - \\
1815 & - & - & - & - & - \\
1816 & 9.17 & - & - & - & - \\
1817 & 8.29 & 24 & - & - & - \\
1818 & 8 & - & - & - & - \\
1819 & 9 & - & - & - & - \\
1820 & 8 & - & - & - & - \\
1821 & 9 & - & - & - & - \\
1822 & 8 & - & - & & - \\
1823 & 8 & & - & - & -
\end{tabular}




\begin{tabular}{|c|c|c|c|c|c|}
\hline Año & $\begin{array}{c}\text { Peón rural } \\
\text { mensual } \\
\text { Col. } 1\end{array}$ & $\begin{array}{c}\text { Peón rural } \\
\text { diario }^{a} \\
\text { Col. } 2\end{array}$ & $\begin{array}{c}\text { Capataz } \\
\text { Col. } 3\end{array}$ & $\begin{array}{c}\text { Capataz/ } \\
\text { peón }\end{array}$ & $\begin{array}{c}\text { Jornalero/ } \\
\text { peón }\end{array}$ \\
\hline 1824 & 12 & - & - & - & - \\
\hline 1825 & - & - & - & - & - \\
\hline 1826 & 11.66 & 18.44 & - & - & 1.58 \\
\hline 1827 & 13 & 28.75 & - & - & - \\
\hline 1828 & 12.94 & 29 & - & - & 2.24 \\
\hline 1829 & 14.59 & 45.44 & 40.50 & 2.78 & 3.11 \\
\hline 1830 & 18.14 & 30 & 30.68 & 1.69 & 1.65 \\
\hline 1831 & 19.08 & 30 & 24.75 & 1.30 & 1.57 \\
\hline 1832 & 21.67 & - & 20 & 0.92 & - \\
\hline 1833 & 29.42 & - & 30 & 1.02 & - \\
\hline 1834 & 32.40 & - & 30 & 0.93 & - \\
\hline 1835 & 37.95 & - & 52 & 1.37 & - \\
\hline 1836 & 37.37 & - & 54.29 & 1.45 & - \\
\hline 1837 & 37.98 & - & 50 & 1.32 & - \\
\hline 1838 & 39.35 & 75 & 50 & 1.27 & 1.91 \\
\hline 1839 & 39.41 & 75 & 50 & 1.27 & 1.90 \\
\hline 1840 & 45 & 90 & 45 & 1 & 2 \\
\hline 1841 & 60 & - & - & - & - \\
\hline 1842 & 40.26 & - & 50 & 1.24 & - \\
\hline 1843 & 40 & - & 50 & 1.25 & - \\
\hline 1844 & 100 & 225 & 150 & 1.50 & 2.25 \\
\hline 1845 & 100 & 225 & 150 & 1.50 & 2.25 \\
\hline 1846 & 50 & 225 & 150 & 3 & 4.50 \\
\hline 1847 & - & 225 & 150 & - & - \\
\hline 1848 & - & - & - & - & - \\
\hline 1849 & 120 & 346.88 & 175 & 1.46 & 2.89 \\
\hline 1850 & 135 & 119.32 & - & - & - \\
\hline 1851 & - & - & - & - & - \\
\hline 1852 & - & - & - & - & - \\
\hline 1853 & - & - & - & - & - \\
\hline 1854 & 60 & 315.37 & - & - & 5.26 \\
\hline 1855 & - & - & - & - & - \\
\hline 1856 & - & - & - & - & - \\
\hline 1857 & - & - & - & - & - \\
\hline 1858 & 150 & - & 235.29 & 1.57 & - \\
\hline 1859 & 150 & 358.78 & 250 & 1.67 & - \\
\hline 1860 & - & 409.82 & - & - & - \\
\hline 1861 & 150 & 355.90 & 200 & 1.33 & - \\
\hline
\end{tabular}




\begin{tabular}{cccccc} 
Peón rural & $\begin{array}{c}\text { Peón rural } \\
\text { diario }\end{array}$ & Capataz & Capataz & Jornalero/ \\
Añón & Cón & peón \\
1862 & Col. 1 & Col. 2 & Col. 3 & & \\
1863 & 150 & 405 & 200 & 1.33 & - \\
1864 & 196 & 450 & 435.71 & 2.22 & - \\
1865 & - & - & - & - & - \\
1866 & - & - & - & - & - \\
1867 & - & - & - & - & - \\
1868 & - & - & - & - & - \\
\hline
\end{tabular}

${ }^{a}$ Considerando quince días de trabajo al mes.

Fuente: véase gráfica 1 .

\section{LISTA DE REFRENCIAS}

Allen, R. C. (2001). The great divergence in European wages and prices from the Middle Ages to the first World War. Explorations in Economic History, 38, 411-447.

Allen, R. C., Murphy, T. E., y Schneider, E. (julio, 2011). The colonial origins of the divergence in the Americas: A labour market approach. Working Paper, 402.

Álvarez, J. (1929). Temas de historia económica. Buenos Aires: El Ateneo.

Amaral, S. (1989). Alta inflación y precios relativos: el pago de las obligaciones en Buenos Aires (1826-1834). El Trimestre Económico, 56(221), 163-191.

BARBA, F. (1999). Aproximación al estudio de los precios y salarios en Buenos Aires desde fines del siglo XVIII hasta 1860. La Plata: Ediciones Universidad Nacional de la Plata.

Broadberry, S. G. (2006). The early modern great divergence: Wages, prices and economic development in Europe and Asia, 1500-1800. Economic History Review, $59(1), 2-31$.

Brown, J. (2002), Historia socioeconómica de la Argentina. 1776-1860. Buenos Aires: Siglo XXI.

Cuesta, M. (2009). Precios, población, impuestos y producción. La economía de Buenos Aires en el siglo XVIII. Buenos Aires: Temas Grupo Editorial.

Dobado, R. y García, H. (2010). Colonial origins of inequality in Hispanic America? Some reflections based on new empirical evidence. Revista de Historia Económica/ Journal of Iberian and Latin American Economic History, 28(2), 253-277.

FRADKIN, R. (2010). Las formas de hacer la guerra en el litoral rioplatense. En S. BANDIERI (comp.), La historia económica y los procesos de independencia en la América hispana (pp. 167-214). Buenos Aires: Prometeo Libros.

Fuente, D. G. (1872). Primer censo de la República Argentina verificado en los días 15, 16 y 17 de septiembre de 1869. Buenos Aires: Imprenta del Porvenir. 
Garavaglia, J. C. (1999). Pastores y labradores de Buenos Aires. Una historia agraria de la campaña bonaerense 1700-1830. Buenos Aires: Ediciones de la Flor.

Garavaglia, J. C. (2003). Ejército y milicia: los campesinos bonaerenses y el peso de las exigencias militares (1810-1860). Anuario IEHS, 18, 153-187.

Garavaglia, J. C. (2004). La economía rural en la campaña de Buenos Aires vista a través de sus precios: (1756-1852). En R. Fradkin y J. C. Garavaglia (comps.), En busca de un tiempo perdido. La economía de Buenos Aires en el país de la abundancia 1750-1865 (pp. 107-158). Buenos Aires: Prometeo.

Garavaglia, J. C. (2011). La burocracia en el Río de la Plata. Buenos Aires, 1800-1861. Anuario IEHS, 25, 119-144.

Garrabou, R. y Tello, E. (2002). Salario como coste, salario como ingreso: el precio de los jornales agrícolas en la Cataluña contemporánea, 1727-1930. En J. M. MARTíNEZ (ed.), El nivel de vida en la España rural. Siglos XVIII-XX (pp. 113-183). Alicante: Universidad de Alicante.

Gelman, J. (1999). Las condiciones del crecimiento estanciero en el Buenos Aires de la primera mitad del siglo XIX. Trabajo, salarios y conflicto en las estancias de Rosas. En J. Gelman, J. C. Garavaglia y B. Zeberio (comps.), Expansión capitalista y transformaciones regionales. Relaciones sociales y empresas agrarias en la Argentina del siglo XIX (pp. 75-120). Buenos Aires: La Colmena/Universidad Nacional del Centro de la Provincia de Buenos Aires.

Gelman, J. y Santilli, D. (2006). De Rivadavia a Rosas. Desigualdad y crecimiento económico. Buenos Aires: Siglo XXI.

Gelman, J. y SAntilli, D. (2011). ¿Cómo explicar la creciente desigualdad? La propiedad de la tierra en Buenos Aires entre 1839 y 1867. En J. GELMAn (comp.), El mapa de la desigualdad en la Argentina del siglo XIX (pp. 171-218). Buenos Aires: Prohistoria.

Grupo de InVESTigación En Historia RuRAL Rioplatense (2004). La sociedad rural bonaerense a principios del siglo XIX. Un análisis a partir de las categorías ocupacionales. En R. Fradkin y J. C. Garavaglia (comps.), En busca de un tiempo perdido. La economía de Buenos Aires en el país de la abundancia 1750-1865 (pp. 21-64). Buenos Aires: Prometeo Libros.

Halperin, T. (1978a). Bloqueos, emisiones monetarias y precios en el Buenos Aires rosista (1838-1850). En F. Miró y P. Franklin (eds.), Historia, problema y promesa. Homenaje a J. Basadre (pp. 307-341). Lima: Pontificia Universidad Católica del Perú. Halperin, T. (1978b). Militarización revolucionaria en Buenos Aires, 1806-1815. En T. Halperin Donghi et al. (comp.), El ocaso del orden colonial en Hispanoamérica (pp. 122-158). Buenos Aires: Sudamericana.

IRIGOIN, M. A. (2004). La expansión ganadera en la campaña de Buenos Aires, 18201860: ¿una consecuencia de la financiación inflacionaria del déficit fiscal? En R. Fradkin y J. C. Garavaglia (comps.), En busca de un tiempo perdido. La economía de Buenos Aires en el país de la abundancia 1750-1865 (pp. 287-330). Buenos Aires: Prometeo. 
Johnson, L. (1990). Salarios precios y costo de vida en el Buenos Aires colonial tardío. Boletín del Instituto de Historia Argentina y Americana Dr. Emilio Ravignani, 2, 133-157.

Johnson, L. (1992). Perspectivas encontradas: Romano, Johnson y la historia de precios del Buenos Aires colonial. Boletín del Instituto de Historia Argentina y Americana Dr. Emilio Ravignani, 6, 163-171.

Johnson, L. L. (2011). Workshop of revolution. Plebeian Buenos Aires and the Atlantic world, 1776-1810. Durham y Londres: Duke University Press.

KuZnets, S. (1966). Modern economic growth. New Haven: Yale University Press.

Lindert, P. H. y Williamson, J. G. (1980). American inequality. A macroeconomic history. Nueva York: Academic Press.

Llopis, E. y García, H. (2011). Precios y salarios en Madrid, 1680-1800. Investigaciones en Historia Económica, 7(2), 295-309.

Margo, R. A. (1999). The history of wage inequality in America, 1820 to 1970. Working Paper, 286. Nueva York: The Levy Economics Institute of Bard College.

MARgO, R. A. (2000). Wages and labor markets in the United States, 1820 to 1860. Chicago: Chicago University.

MAYO, C. (1995). Estancia y sociedad en la pampa 1740-1820. Buenos Aires: Biblos.

MAYO, C. (2000). Vivir en la frontera: la casa, la dieta, la pulpería, la escuela, 1770-1870. Buenos Aires: Biblos.

Pomeranz, K. (2000). The great divergence: China, Europe, and the making of the modern world economy. Princeton: Princeton University Press.

Rabinovich, A. M. (2011). El fenómeno de la deserción en las guerras de la revolución e independencia del Río de la Plata: 1810-1829. Estudios Interdisciplinarios de América Latina y el Caribe, 22, 33-56.

Romano, R. (1966). Cuestiones de historia económica latinoamericana. Caracas: Universidad Central de Venezuela.

Romano, R. (1992). De nuevo acerca del movimiento de precios en Buenos Aires en el siglo XVIII. Boletín del Instituto de Historia Argentina y Americana Dr. Emilio Ravignani, 6, 149-162.

Sábato, H. y Romero, L. A. (1992). Los trabajadores de Buenos Aires. La experiencia del mercado: 1850-1880. Buenos Aires: Sudamericana.

TAYLOR, A. M. y TAYLOR, M. P. (2004). The purchasing power parity debate. Cambridge: National Bureau of Economic Research.

VAN Leeuwen, B. (2004). Wage differentials and economic growth in India, Indonesia and Japan, 1800-2000. World Economic History Congress, Utrecht.

Van Zanden, J. L. (1999). Wages and the standard of living in Europe, 1500-1800. European Review of Economic History, 3(2), 175-197.

VAn Zanden, J. L. (2009). The skill premium and the "great divergence". European Review of Economic History, 13, 121-153. 